\title{
Formando Cidadãos para a Cidadania e Controle Social: Levantamentos de uma Experiência
}

\section{Educating Citizens for Citizenship and Social Control: Notes on an Experiment}

\section{Cassyra Lucia Correa Vuolo', Cristiano Maciel $^{2}$, Anayna Aparecida Corrêa e Barros Auerswald ${ }^{1}$, Rosana Abutakka dos Anjos ${ }^{2}$, Alexandre Martins dos Anjos ${ }^{2}$, Claudete Silva de Oliveira ${ }^{3}$, Débora Pedrotti Mansilla ${ }^{2}$}

${ }^{1}$ Tribunal de Contas do Estado de Mato Grosso Cuiabá, Mato Grosso - Brasil

${ }^{2}$ Universidade Federal de Mato Grosso Cuiabá, Mato Grosso - Brasil

${ }^{3}$ Fundação de Apoio da Universidade Federal de Mato Grosso Cuiabá, Mato Grosso - Brasil

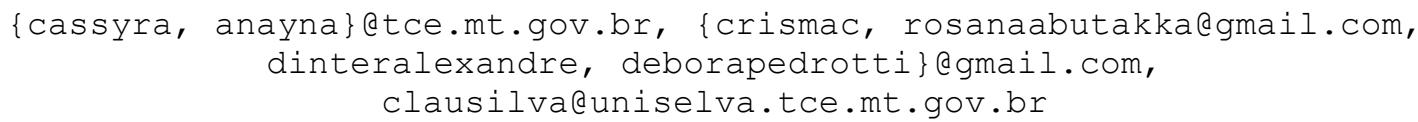

\begin{abstract}
Citizens must be informed and motivated to play an active role in democracy, effectively participating in public life. One of the strategies for that to happen is the use of online education to bridge the gap between government and citizens. However, how do strategies adopted by the Mato Grosso State Audit Court and UFMT in development courses focusing on citizenship and social control increase the number of successful students and improve the effectiveness of the courses? This research analyzes data from the last seven years of the outreach course "Citizenship and social control", offered as a product of a partnership among different institutions. Data show not only citizens' interest, but also the capillarity of this strategy, which reaches people from different provinces, social groups and areas. Thereby, government and society are benefited, as citizens become more informed and engaged in public life.
\end{abstract}

Keywords. Online education; social control; citizenship, Court of Auditors.

Resumo. Um dos caminhos para estímulo ao engajamento e a participação na vida pública é o uso de educação a distância para aproximação do debate entre governo e cidadãos. Todavia, como as estratégias utilizadas, pelo TCEMT e UFMT, no curso de formação de cidadãos para o exercício da cidadania e do controle social, elevam o número de capacitados e melhoram a efetividade do curso? Para responder tal questão, esta pesquisa analisa dados dos últimos sete anos do curso de extensão "Cidadania e controle social",

Cite as: Vuolo, C. L. C.; Maciel, C.; Auerswald, A. A. C. B.; Dos Anjos, R. A.; Dos Anjos, A. M.; De Oliveira, C. S. \& Mansilla, D.P. (2021). Educating Citizens for Citizenship and Social Control: Notes on an Experiment (Formando Cidadãos para a Cidadania e Controle Social: Levantamentos de uma Experiência). iSys: Revista Brasileira de Sistemas de Informação (Brazilian Journal of Information Systems), 14(3), 47-67. DOI: 10.5753/isys.2021.1643 
oferecido como produto de uma parceria entre diferentes instituições governamentais, como ação do Tribunal de Contas do Estado de Mato Grosso - TCE-MT. Os dados mostram não apenas o interesse dos cidadãos, mas também a capilaridade dessa estratégia, que atinge pessoas de diferentes estados, grupos sociais e áreas. Assim, o governo e a sociedade são beneficiados, à medida que os cidadãos se tornam mais bem informados e engajados na vida pública.

Palavras-Chave. Educação a distância; cidadania; controle social; tribunal de contas.

\section{Introdução}

A democracia participativa no Brasil tem seu grande marco estabelecido pela Constituição Federal de 1988, a qual, pautando-se pelos princípios da descentralização e da participação popular, criou instrumentos para que a sociedade possa exercer o seu papel, participando e controlando as ações do Estado na busca do bem comum e do interesse público. Todavia, a sociedade ainda se mantém numa postura de distanciamento e de cultura reclamatória. O desafio é canalizar essas "reclamações" para a pessoa que possa fazer algo a respeito, principalmente quando estas estão relacionadas à qualidade e à prestação de serviços públicos. Vuolo (2016) afirma que, enquanto cidadãos, é preciso tornar a reclamação uma atividade estratégica de participação para que se possa chegar a resultados positivos de melhoria da gestão pública com controle social.

Contudo, como pressuposto da ação participativa está o acesso à informação e o conhecimento para o exercício da cidadania nos momentos e com as ferramentas adequadas às situações práticas. De acordo com Islam (2008), podemos considerar duas primeiras subáreas de governo eletrônico, e-Informação e e-Consulta, como iniciais no processo para consolidar a e-Democracia. Uma vez que os usuários têm acesso à informação da administração pública e são capazes de utilizar serviços por meio das TIC's, o próximo passo é a promoção da e-Participação entre os cidadãos. . Neste ponto, percebe-se que a sociedade brasileira precisa avançar. Já as instituições públicas devem se esforçar mais para diminuir as distâncias entre as ações do governo e a sociedade. Para Bresser Pereira (1997), "serão tanto mais cidadãos quanto menos forem meros espectadores e maior for seu compromisso com o bem comum ou com o interesse público".

Apesar de um abrangente arcabouço de normas legais e infralegais, voltado para a implementação de mecanismos de democracia participativa, diversas dificuldades têm sido encontradas na utilização desses mecanismos, revelando uma lacuna entre o controle social idealizado pelo ordenamento jurídico e o controle efetivamente praticado pela sociedade (VUOLO, 2016). Para que tenhamos uma democracia forte não basta apenas dar poder ao povo, é preciso fornecer educação para o entendimento da sociedade (ASTROM,2001), investindo na formação do indivíduo através da informação, da discussão e do debate. Neste ponto, no Brasil, os Tribunais de Contas dos Estados (TCE) têm atuado como instituições de controle externo da República Brasileira.

No TCE de Mato Grosso, por exemplo, têm sido implementados programas que capacitam o cidadão a buscar suas decisões e informações relacionadas à gestão pública. O estímulo ao controle social passou a integrar o rol de objetivos institucionais 
estabelecidos pelos planos estratégicos editados a partir de 2005, dando ensejo à realização de diversas ações para seu fortalecimento (GIRATA; MACIEL, 2014). Uma destas experiências exitosas é objeto desta pesquisa, o curso via Educação a Distância (EaD) com o tema "Cidadania e Controle Social", que está inserido no contexto do Programa de Desenvolvimento Institucional Integrado - PDI (TCE-MT, 2013), especificamente no Projeto 02 de Incentivo ao Acesso à Informação e à Consciência Cidadã, que desde sua implantação em 2012 busca estimular o engajamento social mediante o empoderamento, a capacitação de membros dos Conselhos de Políticas Públicas e da sociedade para a prática participativa. Esse curso é executado pelo TCEMT em parceria com a UFMT e sua fundação de apoio.

Ao longo dos últimos anos, o perfil desse cidadão vem se delineando e o seu nível de interesse está refletido, entre outros aspectos, na diminuição da taxa de evasão e no encerramento de inscrição no curso em poucos dias de sua abertura. Assim, faz-se mister, conhecer esse cidadão, para o estabelecimento de estratégias para mantê-lo motivado e ativo no exercício democrático, problematizando se há interesse do cidadão em participar deste tipo de formação e qual sua avaliação do curso realizado. Neste sentido, questiona-se: como as estratégias utilizadas, pelo TCE-MT e UFMT, no curso de formação de cidadãos para o exercício da cidadania e do controle social, elevam o número de capacitados e melhoram a efetividade do curso?

Para investigar tal questão, esta pesquisa traz como objetivo levantar os dados dos últimos sete anos (2013 a 2020) da oferta do curso de extensão de "Cidadania e Controle Social", oferecido pelo TCE/MT, órgão de controle externo, em cooperação com outras instituições, analisando a trajetória do curso. Sob o ponto de vista metodológico, quanto aos objetivos, essa é uma pesquisa descritiva, que tem o intuito de estudar as características de um grupo, neste caso, os participantes do curso ao longo das suas últimas edições. Quanto ao tipo de pesquisa, assume a forma de um levantamento, a fim de obter um conhecimento direto sobre o curso, de forma rápida e econômica, e com uma abordagem quantitativa, fazendo uso de tabelas. Os dados foram coletados após a realização dos cursos, todavia foram analisados de forma geral por meio dos Relatórios Finais de cada edição do curso.

O registro de ações como essa, que redundam em pesquisa e extensão, é de suma importância como incentivo para outras instituições governamentais se aproximarem dos cidadãos. Reforça-se que não foram encontrados na literatura o registro de outras estratégias com o mesmo enfoque desta, motivo pelos quais não foram realizadas análises comparativas. Todavia, algumas experiências com educação a distância e controle social de outros tribunais de contas de estados são comentadas. Ainda, cabe ressaltar que esta é uma versão estendida do artigo originalmente publicado no Workshop de Computação Aplicada em Governo Eletrônico (VUOLO et al., 2020).

O artigo está estruturado como segue. Após esta introdução, na seção 2, são apresentadas as bases teóricas que apoiam as estratégias adotadas, incluindo aparatos legais, aspectos do uso de tecnologia pelo governo e experiências de outros tribunais. Após, apresenta-se o levantamento de dados de realização do curso, nos últimos sete anos. Quanto à análise, é apresentado para cada realização do curso, o perfil dos participantes, o aproveitamento do curso e a avaliação pelos participantes, além de alguns outros dados gerais. Por fim, seguem as considerações finais e as referências bibliográficas. 


\section{Bases teóricas, legais e seus elos}

O Brasil adota o modelo Latino-Americano, no qual o controle externo é exercido pelos Tribunais de Contas que possuem natureza de órgãos constitucionais dotados de autonomia administrativa e financeira sem qualquer relação de subordinação com os Poderes Executivo, Legislativo e Judiciário. Moreira Neto (2004, p. 113-114) e Brito (2001) sustentam que o controle externo realizado pelos Tribunais de Contas do Brasil, órgãos governamentais dos Estados do Brasil, vai além da análise dos aspectos orçamentários e financeiros para contribuir com o aprimoramento da gestão, o equilíbrio entre os Poderes no Estado Democrático de Direito, a mensuração da efetividade da gestão pública e a disponibilização de informações e de mecanismos capazes de viabilizar a inserção do cidadão no processo de definição, implementação e avaliação da ação pública. Por certo que, a partir deste ponto, a transparência e a participação da sociedade passam a ser fatores determinantes para que a sociedade realize um efetivo controle sobre a gestão pública. Desta forma, dá-se o controle social da Administração Pública.

Foi em resposta a estas novas demandas características do terceiro milênio que o Tribunal de Contas de Mato Grosso - TCE-MT, em 2005, deu início a um amplo processo de modernização institucional com o intuito de transformar a Instituição em referência no Controle Externo de contas públicas e um instrumento de cidadania estimulando ações de controle social, sendo a capacitação via $\mathrm{EaD}$ parte do conjunto mais amplo de ações que visam a melhoria da gestão e a formação de uma consciência cidadã em articulação com o controle interno e o controle externo.

Este pano de fundo, em 2012, levou à institucionalização no TCE-MT do Programa de Desenvolvimentos Institucional Integrado - PDI (TCE-MT, 2013) com o objetivo de contribuir para a melhoria da eficiência dos serviços públicos, o estímulo à transparência e à consciência cidadã, através do fomento, do incentivo e da adoção de modelos de gestão voltados para resultados concretos em benefícios da sociedade. Compõem o PDI do TCE-MT os projetos: Projeto 1: Apoio ao Planejamento Estratégico; Projeto 2: Incentivo ao Acesso à Informação e à Consciência Cidadã; Projeto 3: Orientação por meio de Cursos Presenciais e a Distância; Projeto 4: Controle Gerencial Utilizando o Sistema Geo-Obras; Projeto 5: Modernização Institucional e Projeto 6: TCEndo Cidadania.

O Curso de Extensão via EaD está inserido no PDI, dentro do Projeto 2 Incentivo ao Acesso à Informação e à Consciência Cidadã, tendo sua criação sido baseada no diagnóstico realizado em 2012 pelo TCE-MT em parceria com a Universidade Federal de Mato Grosso (UFMT), que apontou a necessidade de promover capacitação continuada para os conselheiros dos Conselhos de Políticas Públicas, visando ao fortalecimento da democracia participativa.

Apesar de todos os esforços das instituições, especialmente do TCE-MT, para se aproximar da sociedade, a distância entre o povo e as instâncias decisórias do Estado nas sociedades contemporâneas é uma realidade bastante complexa.

Ao refletir acerca dessa temática, Benevides (1996) aborda a necessidade de se implantarem mudanças no plano das mentalidades e dos costumes do povo brasileiro. Isso somente é possível mudar por meio de uma tarefa coletiva, e não individual. Com efeito, essa reflexão autocrítica, ao invés da culpabilização individual, pressupõe a 
responsabilidade coletiva. Coloca os atores sociais em relações horizontalizadas do ponto de vista do valor das pessoas, de suas crenças e de seus desejos (MENDONÇA, 2000). Assim sendo, a oferta do curso de Cidadania e Controle Social na modalidade $\mathrm{EaD}$ atende à demanda social e está amparado nos cenários legal, político e social favoráveis à democracia participativa e a inclusão da sociedade nas decisões públicas por meio de ferramentas tecnológicas e de amplo acesso.

No campo do cenário legal, de forma geral, uma série de legislações foram criadas para dar suporte a cidadania - Constituição Cidadã 1998 (BRASIL, 1988), a efetividade - Emenda Constitucional 19/1998) (BRASIL, 1998), responsabilização - Lei de Responsabilidade Fiscal 101/200 (BR, LRF 101, 2000), transparência - Lei 131/2009 (BR, 2009) e Lei 12.527/2011 (BR, 2011). Veja a Figura 1.

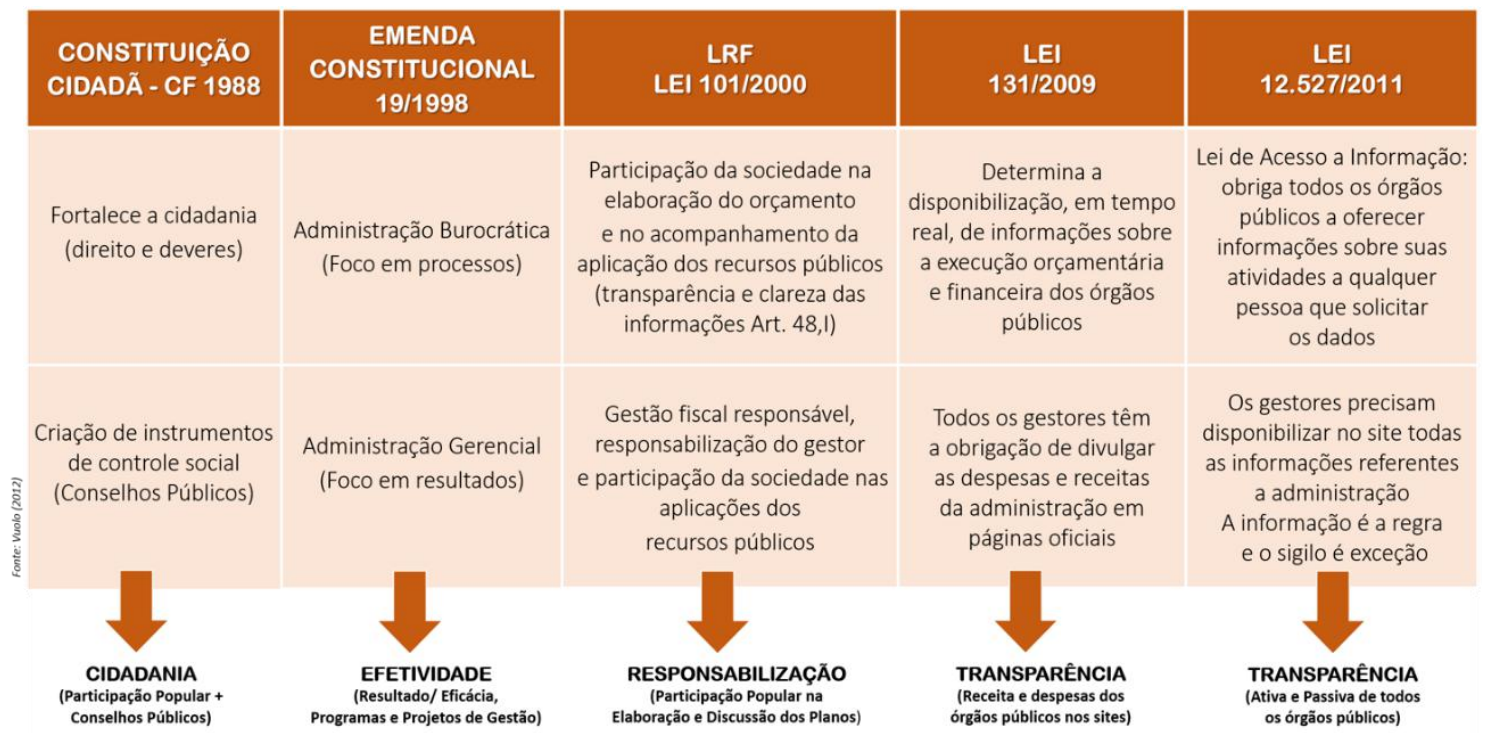

Figura 1. Cenário Legal (Fonte: Arquivos de Dados da SAI-TCE-MT - Secretaria de Articulação Institucional e Desenvolvimento da Cidadania (SAI) do Tribunal de Contas de Mato Grosso (TCE-MT))

Vuolo (2008, p. 50) ressalta que o processo de democratização no movimento político brasileiro imprime novos significados na relação de quem governa e é governado, assim, para a autora, a democracia passa a ser embasada em confiança recíproca, com competência nos esforços, transparência nas ações e eficiência no uso dos meios, deixando de ser uma técnica formal de escolha periódica de quem governa para ser uma escolha permanente de como querem ser governados. Para Barber (2004), a democracia forte baseia-se na ideia de uma comunidade autônoma de cidadãos que estão unidos mais pela educação cívica do que por interesses homogêneos.

Quanto ao cenário político institucional, destaca-se neste estudo, a consolidação dos Tribunais de Contas como instituições essenciais para o controle externo da gestão dos recursos públicos. Uma instituição republicana e constitucionalmente responsável pelo controle das contas públicas em benefício da sociedade. O PDI do TCE-MT, em 2012, e o Curso de Cidadania e Controle Social, em 2013, surgem para dar cumprimento a este cenário. Por isso, esta pesquisa apresenta os dados do curso a partir de 2013.

No tocante ao cenário social, há a possibilidade de participação do cidadão no fortalecimento democrático, o que pode ser viabilizado com o uso de tecnologias, desde 
que esse esteja devidamente informado (MACIEL, ROQUE, GARCIA, 2009). Uma série de distintas tecnologias têm sido usadas pelos órgãos governamentais (MACIEL et al., 2016). Além de tecnologias oficiais de e-Participação, ou seja, das plataformas governamentais para e-participação, os cidadãos fazem uso de redes sociais e/ou comunidades virtuais para tal (MACIEL, GARCIA, PINTO, 2020). Para esses autores "conscientizar o cidadão a participar de assuntos de interesse público é um grande desafio e muito se tem discutido sobre o potencial das tecnologias de informação e comunicação (TICs) para ampliar a capacidade de participação desses cidadãos através de uma interação bidirecional, descentralizada e não-hierarquizada.”. Neste sentido, a proposta de um curso a distância pelo TCE-MT constitui-se como um canal de diálogo com a sociedade, sendo que as transformações políticas e legais dão alicerce para o surgimento de cidadãos cada vez mais interessados em acompanhar os gastos públicos e receber informações relacionadas à gestão local. A democracia representativa, por si só, não vem conseguindo atender os anseios da sociedade, o fortalecimento da democracia participativa tem ganhado destaque procurando aproximar a gestão pública do controle dos cidadãos (VUOLO, 2008). Neste sentido, participação significa a ação empreendida pelo cidadão no compartilhamento do poder com agentes públicos visando à tomada de decisão com a comunidade. $O$ engajamento social contribui para a efetivação dos direitos sociais universais como a educação, a saúde, a alimentação, o trabalho, a moradia, o lazer, a segurança, entre outros.

Neste contexto, outro conceito importante é a responsabilidade social. Para Campos (1990), a expressão "accountability" está relacionada com responsividade e o dever de prestar contas, com os mecanismos de controle social e como estes sustentam e aprofundam o processo democrático. Se por um lado a responsabilidade social é fundamental para a preservação da democracia, por outro é indispensável a participação dos cidadãos para que ela se realize. Ser cidadão num regime democrático significa possuir uma série de direitos e obrigações sociais (ROBERTS, 2004). Para tanto, é necessário a existência de instrumentos de reflexão e debate das questões sociais relacionadas aos interesses coletivos, para dar suporte à responsabilização e contribuir para que a sociedade tenha oportunidades de participação em temas de interesse público.

Akutsu e Pinho (2002, p. 723-745) relacionaram a ampla difusão de informações via "governo eletrônico" ao fortalecimento da democracia e da responsabilidade social e como esta prática favorece a transparência, a responsabilização, a prestação de contas (principalmente na execução orçamentária) e a montagem de estratégias sociais para ações reivindicatórias. Esta prática exige uma postura favorável da estrutura do Estado e uma permeabilidade às pressões da sociedade e, ao mesmo tempo, requer atores sociais preparados para legitimar a representação, para manipular e processar informações relacionadas às políticas públicas. Ou seja, é necessário que os atores e movimentos sociais dominem uma expertise para dar base de sustentação à ação política que fortaleça a democracia, a governança e os resultados das políticas públicas.

Algumas estratégias podem figurar como meios privilegiados de impulsão desta tendência, inclusive o curso de "Cidadania e Controle Social", direcionado à aplicação dos mecanismos de responsabilidade social. Tal estratégia possui a característica de processo dialógico mediado por tecnologias, opera como instância apta a formar cidadãos com capacidade de realizar o controle social e atuar inclusive no processo de orçamentação participativa (de SOUZA, MACIEL, 2008). 
Nestes cenários, diante dos enormes desafios na gestão dos recursos públicos e de engajamento da sociedade, o uso da educação a distância e de recursos de interação e comunicação propiciados pelas ferramentas tecnológicas permitem orientar e estimular o cidadão ao exercício do controle social de forma pertinente e viável.

Registros de pesquisas no contexto do controle social e da educação a distância no contexto dos Tribunais de Contas dos Estados ainda são escassos. Todavia, alguns trabalhos foram encontrados em uma busca no Google Scholar, os quais são brevemente descritos a seguir:

A pesquisa de Ellery e Vidal (2010) objetivou "resgatar e analisar o processo de introdução da modalidade de educação a distância pelo Tribunal de Contas dos Municípios do Estado do Ceará (TCM-CE), com ênfase no reconhecimento, mapeamento e análise do perfil da formação docente e das estratégias metodológicas adotadas para a viabilização do Curso de Controle Social das Contas Públicas". O foco da pesquisa é nas midias digitais utilizadas neste processo, considerando as mídias da época.

Por sua vez, a pesquisa de Felix e Figueirêdo (2017) visa demonstrar como "a educação corporativa pode ser utilizada como instrumento que proporcione e viabilize a existência desse controle social". Os autores demonstram o estudo com um caso prático, o da implantação do Sistema de Controle dos Atos de Pessoal (Sicap) no Tribunal de Contas do Estado de Roraima.

Já a monografia de Eirado (2017) buscou "identificar as percepções dos servidores do Tribunal de Contas do Distrito Federal sobre o Ensino a Distância". Essa pesquisa foi executada diretamente com servidores e concluiu, entre outros, que eles "se mostram receptivos a usufruírem de todos os benefícios oferecidos pela Educação a Distância.". Ainda, o estudo apoiou a Escola de Contas do orgão no processo de implantação dessa modalidade de ensino.

Os trabalhos supracitados registram diferenciadas estratégias de educação a distância no campo do controle social, todavia as metodologias e tecnologias adotadas se diferem da pesquisa em tela, não sendo possível traçar comparações entre os dados. A seguir, é apresentada a trajetória do curso ao longo dos anos.

\section{O curso e sua trajetória: dados gerais}

O curso de Cidadania e Controle Social via EaD vem sendo ofertado anualmente desde 2013, exceto em 2015 quando o mesmo passou por profundas reformulações (VUOLO, MACIEL, ANJOS, 2018). Entre outros, após essa reformulação, percebeu-se a necessidade de coletar mais dados dos participantes, o que não se fazia nos anos anteriores, fato que nos leva a ter mais informações dos últimos cinco anos de realização do mesmo. Todas as realizações de cursos culminaram na elaboração de um Relatório Final, documento este que serviu de base para o levantamento dos dados apresentado nesta e na próxima seção. Para levantamento destes dados, foram feitas tabelas, gráficos e outros documentos, os quais foram analisados quantitativamente e qualitativamente pelos autores deste artigo. A seguir, tem-se um detalhamento de dados gerais da realização do curso em cada ano.

$\mathrm{Na} 1^{\text {a }}$ Edição do Curso de Extensão "Os Conselhos de Políticas Públicas na Efetivação do Controle Social em Mato Grosso", realizou-se em 2013 nos 20 maiores municípios mato-grossenses adesos ao PDI e foi ministrado via $\mathrm{EaD}$, com apoio da Universidade Federal de Mato Grosso (UFMT). Na ocasião foram ofertadas 400 vagas, 
destinadas exclusivamente para os conselheiros de políticas públicas. Essa edição contou com a participação de cursistas de 26 municípios, uma vez que participaram conselheiros de mais municípios do que os adesos ao PDI.

Em 2014, o TCE promoveu a $2^{\mathrm{a}}$ Edição do Curso de Extensão, disponibilizando 200 vagas para 10 municípios que aderiram ao PDI naquele ano e aos demais municípios mato-grossenses. Neste caso, o público-alvo abrangeu além dos conselheiros de políticas públicas, os membros da sociedade civil. Neste, obteve-se a participação de cursistas de 18 municípios. As capacitações revelaram a importância da formação de conselheiros e cidadãos para que compreendam melhor o funcionamento da gestão pública, nas três esferas de governo, o processo de formulação, implementação e avaliação de políticas públicas, o ciclo orçamentário e o efetivo exercício da cidadania, sobretudo a partir da utilização das informações produzidas pelo órgão de controle externo - o TCE-MT.

Esse processo formativo, nas suas duas primeiras edições apresentou desafios geográficos e culturais que precisavam ser superados, tendo em vista a necessidade de institucionalização de políticas e ações voltadas para a formação dos membros dos Conselhos de Políticas Públicas e membros da sociedade civil, na temática do controle social da Administração Pública. A título de ilustração, a média de distância da capital dos municípios participantes no curso nesses dois primeiros anos ficou em torno de 258 $\mathrm{km}$, sendo o município mais distante, contando com $1007 \mathrm{~km}$.

Para subsidiar o aperfeiçoamento da EaD e medir as ações dos conselheiros após as ações do curso e do PDI, em 2015, foi aplicada uma pesquisa junto aos Conselhos de 41 municípios, que traçou um diagnóstico mais ampliado em relação às atividades de controle social e ao acompanhamento da gestão pública feito pelos Conselhos. Esta pesquisa foi realizada em fases: aplicação do questionário, realização de grupo focal em 6 municípios e a análise dos dados. Por fim, foi desenvolvido um relatório, que expõe de maneira descritiva as respostas coletadas a partir dos questionários, apresentando os resultados referentes ao conjunto dos conselheiros e as falas de outros que participaram dos grupos focais. No total, foram pesquisados 322 conselhos dos 41 municípios analisados, o que nos demonstra uma média de quase 8 conselhos por municípios. Os resultados desta pesquisa foram consolidados em um livro (VUOLO; SILVA; SOUZA, 2017), que registra a experiência dos Conselhos no PDI, a arquitetura, perfil de seus membros, capacidade de desempenho de suas funções e perspectivas dos mesmos.

A $3^{\text {a }}$ edição do curso de extensão, visando o fortalecimento dos Conselhos de Políticas Públicas na Efetivação do Controle Social, foi ministrado para 2000 alunos distribuídos em 40 turmas, um público bastante elevado em relação aos outros cursos que já foram realizados pelo TCE-MT, conforme dados do Relatório do Curso de Extensão via EaD de 2016. O curso atingiu 24 municípios do Estado do MT.

No ano seguinte, a $4^{\circ}$ edição ofereceu 2000 vagas e exigiu uma revisão do Projeto Pedagógico do Curso, incluindo os objetivos de formação, o perfil do estudante/cursista a ser formado, a atualização do material didático e dos meios de acesso para os cursistas, o sistema de tutoria e o sistema de avaliação, conforme dados do Relatório do Curso de Extensão via EaD de 2017. Parte da experiência adquirida nos últimos anos foi publicada no Livro "Educação a distância: [IN]formação em cidadania e controle social" (VUOLO; MACIEL, ANJOS, 2018), editado pelo TCE-MT e a 
UFMT, lançado em 2017, relatando o caminho trilhado, as experiências, as vozes dos tutores, dos alunos e os melhores trabalhos finais relacionados às políticas públicas.

Para elevar o nível de efetividade e eficiência do curso, para a $5^{\text {a }}$ edição foi estabelecida uma meta ousada de aprovação de 50\% dos inscritos uma vez que, em 2018, seria um ano eleitoral e de Copa do Mundo no Brasil, eventos que culturalmente impactam sobremaneira a rotina dos cursistas, das instituições e dos brasileiros de maneira geral. Mesmo com todos esses desafios, o curso em 2018, alcançou uma taxa de aprovação de $87,5 \%$ e com utilização de apenas $14 \%$ do cadastro de reserva. Sobre os cursistas de 2018, houve a presença de cursistas de 111 dos 141 municípios de Mato Grosso, que evidencia o interesse dos cidadãos pela formação em "Cidadania e Controle Social". Outrossim, notou-se inscritos que declararam residir em 61 municípios de outros estados da Federação podendo-se concluir que este curso já ultrapassou as fronteiras deste estado atingindo todas as regiões do país.

Em 2019, o curso ofertou 1000 vagas e obteve 3002 inscrições, de 122 municípios do país. Percebeu-se uma grande procura pelo curso na sua $6^{\mathrm{a}}$ edição, o que pode ser resultado da maturidade que este adquiriu e a continuidade de sua execução, gerando demanda e interesse pelos cidadãos.

$\mathrm{Na} 7^{\mathrm{a}}$ edição do curso, em 2020, foram oferecidas 1000 vagas e foram obtidas 2261 inscrições, de 188 municípios do país e em 100\% dos municípios adesos ao PDI. Embora o número de inscritos tenha superado em mais de $100 \%$ o número de vagas ofertadas, percebe-se uma diminuição em relação ao ano anterior. Uma das hipóteses para tal foi o fato de este ter sido um ano de eleições municipais (em 2016 a procura foi de $154,6 \%$ e em 2020 de 226,1\% ). Veja, na Figura 2, a seguir, uma interface do curso em sua atuação versão. 


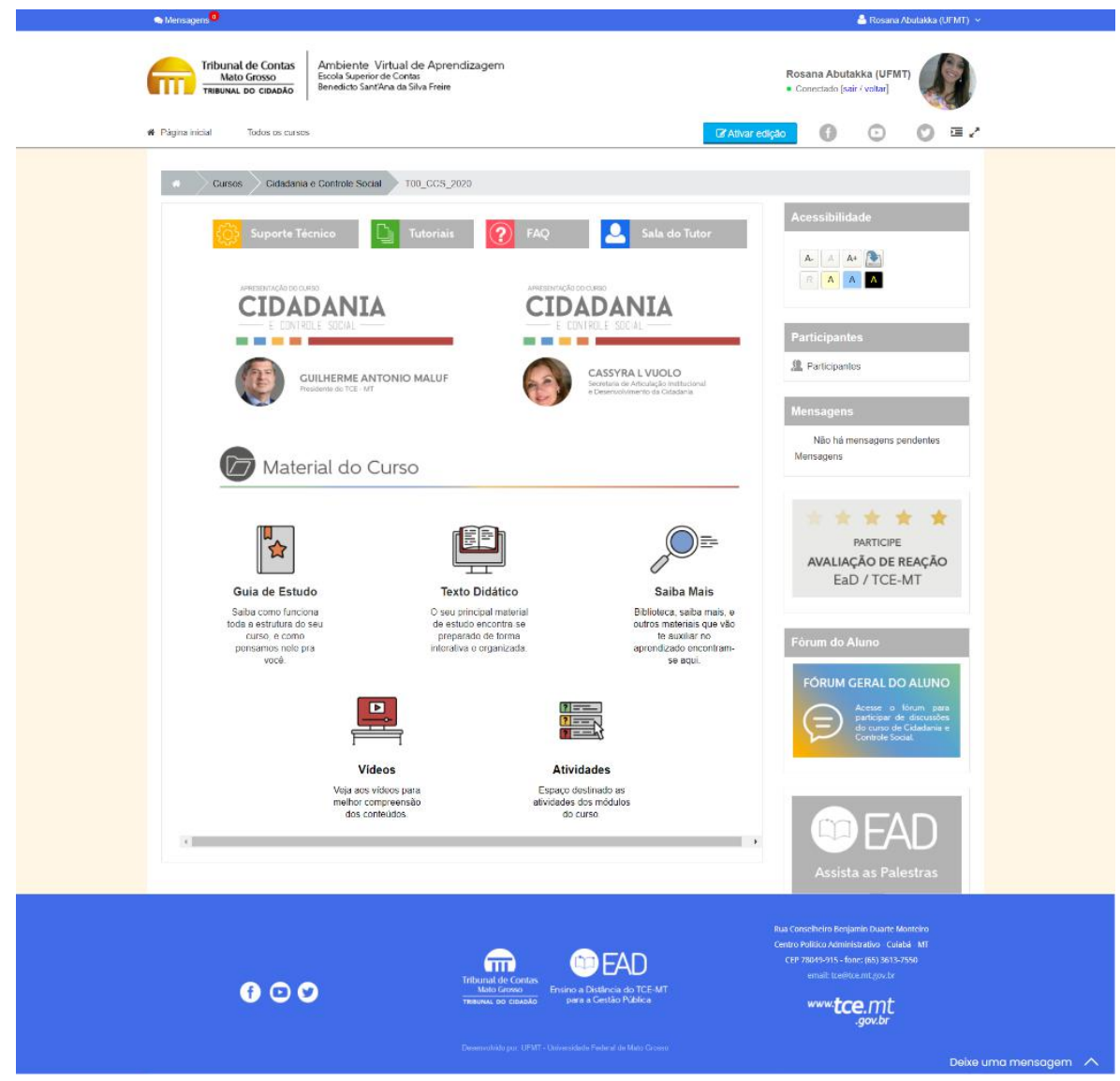

Figura 2: Interface do Curso de Cidadania e Controle Social (https://ead.tce.mt.gov.br/)

Neste ano, o curso se deu $100 \%$ à distância, desde as entrevistas para seleção dos tutores, quanto às reuniões pedagógicas da coordenação pedagógica entre si e com os tutores e a aula inaugural, que até a edição passada foi presencial, é transmitida online no canal YouTube do TCE-MT. O curso aconteceu de 04 de maio a 20 de julho, ou seja, no auge da pandemia causada pelo novo coronavírus Sars-Cov-2. E, mesmo enfrentando adversidades, ele conseguiu manter os cursistas interessados e atingiu $73,14 \%$ de aprovação. Cabe ressaltar que, dos concluintes que se declararam conselheiros de políticas públicas, surpreende que $19,87 \%$ pertenciam à área da saúde, maior percentual apresentado por essa área em todas as edições.

A próxima seção analisa os dados dos cursos, de 2013 a 2020.

\section{Análise dos dados levantados}

Para demonstrar e analisar os dados levantados, optou-se pela divisão desta seção em três: interesse e perfil dos participantes; aproveitamento e avaliação do curso.

\subsection{Interesse e perfil dos participantes}

As análises começam por um ponto central do nosso levantamento, o interesse pelo curso por parte dos cidadãos. Percebe-se, pelos dados dos arquivos e relatórios da SAI do TCE/MT, que houve interesse, sendo o número de inscritos maior que o número de vagas. Em 2013, foram ofertadas 400 vagas sendo inscritos 403 interessados. Em 2014, foram ofertadas 200 vagas e 265 inscritos. Já em 2016 e 2017 foram ofertadas 2000 
vagas, tendo respectivamente 3092 e 3101 inscritos. Em 2018, 2019 e 2020, das 1000 vagas ofertadas, 2342, 3002 e 2261 pessoas respectivamente se inscreveram para o curso. Nos últimos 3 anos, o interesse aumentou, sendo o número de inscritos superior a $100 \%$ do número de vagas.

Baseados nessas informações, vê-se não somente o crescimento do interesse pela temática por parte da população, como também uma melhoria da divulgação do curso, por meio das diversas estratégias criadas pelas entidades envolvidas com essa oferta. De forma geral, as estratégias utilizadas foram: envio de ofício do Presidente do TCE-MT aos prefeitos dos 141 municípios para divulgar o curso; veiculação de reportagens na mídia e vinhetas/entrevistas nas rádios; reuniões com público-alvo; lançamento do curso junto às entidades parceiras, conselhos e instituições de Ensino (2016); e envio de email marketing ao cadastro de reserva. Cabe ressaltar que diversos alunos alegaram conhecer o curso por meio dos anúncios em redes sociais.

O curso, por ser ministrado via Internet, através da educação a distância, permitiu que, nos últimos anos, cidadãos de diferentes Estados se inscrevessem e participassem do mesmo. Porém, por ser ofertado pelo TCE-MT, e por haver maior divulgação dentro deste Estado, há um número elevado de municípios do Estado com cidadãos inscritos, conforme demonstrado na Tabela 1. Além da região Centro-Oeste, na qual se encontra o estado do Mato Grosso, percebe-se um bom interesse de regiões como a Nordeste e Sudeste, especialmente nos anos de 2018 e 2020. Ressalta-se que todos Estados possuem Tribunais de Contas, os quais exercem suas funções junto aos seus municípios.

Tabela 1. Número de municípios com inscritos: outros Estados x Estado de Mato Grosso

\begin{tabular}{|c|c|c|c|c|c|c|c|}
\hline Ano & $\mathbf{2 0 1 3}$ & $\mathbf{2 0 1 4}$ & $\mathbf{2 0 1 6}$ & $\mathbf{2 0 1 7}$ & $\mathbf{2 0 1 8}$ & $\mathbf{2 0 1 9}$ & $\mathbf{2 0 2 0}$ \\
\hline $\begin{array}{c}\text { Municípios de outros Estados com } \\
\text { inscrigos }\end{array}$ & - & - & 11 & 26 & 61 & 33 & 61 \\
\hline $\begin{array}{c}\text { Municípios de Mato Grosso com } \\
\text { inscritos }\end{array}$ & 26 & 24 & 122 & 137 & 111 & 122 & 127 \\
\hline
\end{tabular}

Após o curso, foi realizada pesquisa para verificar por qual meio de comunicação tomaram conhecimento da realização do curso. Foi enviado questionário on-line aos 114 cursistas que se inscreveram no Portal do TCE para participar do EaD CCS, em 2020. Embora obtendo apenas 16 respostas percebe-se que 5 ficaram sabendo do curso por meio de WhatsApp, 2 via Facebook e 2 via Instagram.

É importante pontuar que o curso foi pensado inicialmente para o público de conselheiros de políticas públicas, pelo papel que estes desempenham em seus municípios, conforme comentado anteriormente. No entanto, as ações para envolvimento deste público se iniciaram em 2016 e, desde então, tem demonstrado leve crescimento no número de concluintes, conforme Tabela 2. Analisando as áreas de atuação destes conselheiros, percebe-se que a maioria é da área da Educação. Conselheiros de áreas como assistência social e saúde também demonstram maior interesse pelo curso. Ressalta-se que nos anos de 2013 e 2014, tal dado não era coletado.

Tabela 2. Percentual de concluintes conselheiros por área de atuação 


\begin{tabular}{|c|c|c|c|c|c|}
\hline Ano & $\mathbf{2 0 1 6}$ & $\mathbf{2 0 1 7}$ & $\mathbf{2 0 1 8}$ & $\mathbf{2 0 1 9}$ & $\mathbf{2 0 2 0}$ \\
\hline Educação & $54 \%$ & $30 \%$ & $32 \%$ & $28,9 \%$ & $44,81 \%$ \\
\hline Social & - & $10 \%$ & $26 \%$ & $8,8 \%$ & $17,66 \%$ \\
\hline Saúde & $3 \%$ & $10 \%$ & $17 \%$ & - & $19,87 \%$ \\
\hline Desenvolvimento & - & $1 \%$ & $8 \%$ & $1,7 \%$ & $7,06 \%$ \\
\hline $\begin{array}{c}\text { Políticas } \\
\text { Públicas }\end{array}$ & - & - & $6 \%$ & $6 \%$ & $1,77 \%$ \\
\hline Meio Ambiente & - & $1 \%$ & $4 \%$ & $16,1 \%$ & $2,24 \%$ \\
\hline Cultura & - & $1 \%$ & $3 \%$ & $1,9 \%$ & $0,88 \%$ \\
\hline Segurança & - & $3 \%$ & $3 \%$ & $1,5 \%$ & $1,10 \%$ \\
\hline Outros & $43 \%$ & $44 \%$ & $1 \%$ & $35,1 \%$ & $4,64 \%$ \\
\hline
\end{tabular}

Fonte: Arquivos da Sai - TCE/MT - Relatórios do Curso de Extensão anos 2016 a 2020.

Com relação ao sexo, em todos os anos, percebe-se uma maior atuação das mulheres entre os concluintes do curso. O porque deste interesse maior por parte das mulheres ainda não foi objeto de estudo, mas é um dado que suscita maiores reflexões. Veja Tabela 3.

Tabela 3. Percentual de mulheres que concluíram o curso

\begin{tabular}{|c|c|c|c|c|c|c|c|c|}
\hline Ano & $\mathbf{2 0 1 3}$ & $\mathbf{2 0 1 4}$ & $\mathbf{2 0 1 5}$ & $\mathbf{2 0 1 6}$ & $\mathbf{2 0 1 7}$ & $\mathbf{2 0 1 8}$ & $\mathbf{2 0 1 9}$ & $\mathbf{2 0 2 0}$ \\
\hline $\begin{array}{c}\text { Mulhere } \\
\text { s }\end{array}$ & $64 \%$ & $76 \%$ & - & $81 \%$ & $67 \%$ & $71 \%$ & $71,5 \%$ & 74,63 \\
\hline Homens & $36 \%$ & $24 \%$ & - & $19 \%$ & $33 \%$ & $29 \%$ & $28,5 \%$ & 25,37 \\
\hline \multicolumn{7}{c|}{ Fonte: Arquivos da Sai - TCE/MT }
\end{tabular}

Outro importante dado é a profissão dos participantes, dado coletado entre 2016 e 2020. Em 2016 e 2017, a lista de profissões ofertada aos cidadãos para escolha foi diferente da de 2018, sendo essa última exportada dos dados informados pela Receita Federal. Ainda, havia um campo denominado "outros", no qual os cursistas poderiam declarar sua profissão. Assim, percebe-se que alguns acabaram por declarar os cargos ocupados nos poderes públicos, ao invés das profissões de fato. Optou-se por manter este dado desta forma, para ser mais fidedigno com o informado pelo cidadão. Em 2016, considerando profissões e cargos, 39 diferentes denominações foram apontadas, sendo as de maior ocorrência "Conselheiro de políticas públicas" e "estudante". Em 2017 e 2018, o cargo mais apontado pelos participantes foi o de agente administrativo (nomeados como administrativo, agente, agente de serviços administrativos, gestor, técnico, entre outros), ligados aos governos, sejam eles municipais, estaduais ou federais. Quanto as profissões, de forma geral, as três mais escolhidas foram professor, estudante e contador. Ressalta-se a grande variedade de profissões/cargos ocupados pelos participantes, sendo que o curso atinge desde cidadãos em posições mais operacionais como aqueles que ocupam cargos estratégicos. Em 2017, foram apontadas 30 diferentes profissões e, em 2018 e 2019, 32 profissões. Já em 2020, foram informadas 103 profissões, havendo uma mudança significativa no número dada a mudança de metodologia para coleta do dado. Em geral, percebe-se, pelo conjunto de profissões, que o curso tem participação de cidadãos de diferentes esferas da sociedade. 


\subsection{Aproveitamento do curso}

Ao longo dos anos, percebeu-se que o número de cidadãos que concluíam o curso era baixo, sendo elevado o percentual de evasão. Estratégias foram criadas para melhoramentos desses números e, em comparação com os dados iniciais merecendo destaque o ano de 2018, esse percentual baixou consideravelmente. De 2014 a 2018 não foram computados os cursistas inseridos/substituídos após o início do curso. Em 2019, além das mil vagas ofertadas, foram inseridos 243 em substituição aos desistentes. Para o cálculo, considera-se então o total de 1.243 inscritos, correspondendo a 74,73\%. Em 2020, foram inseridos 266 em substituição aos desistentes. Assim, o total de 1.266 cursista redunda em $73,14 \%$ de aprovação. Apesar de os dados terem variação na sua coleta, dado o aprimoramento das estratégias, pode-se afirmar que, em 2019 e 2020, houve elevação nos índices. As taxas de evasão de 19,5\% e 20,69\% respectivamente representam valores bem abaixo dos $50 \%$ apresentados pelas instituições que oferecem essa modalidade de cursos, de acordo com o censo realizado pela Associação Brasileira de Ensino a Distância em 2015 (Oliveira, 2017). Veja a conforme Tabela 4.

Tabela 4. Relação vagas, aprovação e evasão

\begin{tabular}{|c|c|c|c|c|}
\hline Ano & $\begin{array}{c}\text { Vagas } \\
\text { ofertadas }\end{array}$ & $\begin{array}{c}\text { Aprovado } \\
\mathbf{s}\end{array}$ & Taxa de aprovação & Taxa de evasão \\
\hline 2013 & 400 & 66 & $16 \%$ & $84 \%$ \\
\hline 2014 & 200 & 56 & $28 \%$ & $72 \%$ \\
\hline 2015 & - & - & - & - \\
\hline 2016 & 2000 & 679 & $34 \%$ & $50 \%$ \\
\hline 2017 & 2000 & 1416 & $71 \%$ & $11 \%$ \\
\hline 2018 & 1000 & 875 & $87,5 \%$ & $2 \%$ \\
\hline 2019 & 1000 & 929 & $74.7 \%$ & $19,5 \%$ \\
\hline 2020 & 1000 & 926 & $73,1 \%$ & $20,6 \%$ \\
\hline \multicolumn{2}{|c|}{ Fonte: Arquivos da Sai - TCE/MT-Relatórios do Curso de Extensão. } \\
\hline
\end{tabular}

Com base nas evasões, foram formuladas estratégias para que os alunos permanecessem arraigados ao curso até o final. De 2016 a 2019, os cursistas precisariam elaborar um trabalho final. Consideravam-se aptos para receber $o$ certificado de conclusão do curso aqueles cursistas que chegassem na etapa da entrega do trabalho.

Mesmo participando do curso como um todo, muitos dos alunos acabavam não fazendo essa atividade final. Para esses alunos, era atribuído um certificado de participação. Percebe-se que com a implementação da entrega do trabalho final, houve uma grande participação e interesse por parte dos cursistas. No ano de 2016, todos os cursistas que entregaram os trabalhos foram aprovados. Em 2017, os 10 melhores trabalhos foram escolhidos para compor um livro (VUOLO; MACIEL; ANJOS, 2018). A totalidade dos trabalhos desenvolvidos foram enviados pelo Presidente do TCE-MT para todos os prefeitos do estado. Desta forma, estimula-se a proposição de ideias pelos cidadãos, as quais podem fomentar políticas públicas para os municípios.

Percebeu-se grande motivação dos cursistas em 2018 ano em que foi incluída uma unidade no último módulo com temas específicos sobre vários aspectos dos Conselhos de Políticas Públicas e incluindo atividades práticas com base em situações 
hipotéticas. Já em 2019 o destaque no campo pedagógico foi a inclusão de atividade relacionada aos Portais dos Municípios aplicando-se a Lei da Transparência. Tendo em vista a dificuldade dos cursistas em realizarem essa atividade, bem como o tempo e atenção dispendida pelos tutores, optou-se por não mais exigir a elaboração do trabalho final e focar nessa atividade.

Em 2020, a aula inaugural online e a live "Transparência e Controle Social" foram as estratégias adotadas para motivar os cursistas e mitigar a evasão. A primeira está atualmente com 2,6 mil visualizações no canal do Youtube do TCE-MT e a segunda com 1,7 mil visualizações [TCE MT 2020] ${ }^{1}$, além de ser um dos sete cursos mais acessados no portal do IRB Conhecimento [IRB 2020].

Maciel, Garcia e Pinto (2020), ao discutirem pontos críticos e desafios da edemocracia, apontam entre os pontos críticos, ou seja, entre os aspectos necessários para se construir a infraestrutura para que a implantação da democracia eletrônica tenha sucesso, o "treinamento dos representantes políticos, dos funcionários públicos e dos cidadãos, incluindo educação para participação popular.”. Neste sentido, a experiência supra apresentada, proporciona aos conselheiros municipais de políticas públicas e aos cidadãos o conhecimento sobre temas importantes no tocante ao controle social, indicando ainda como eles podem exercer seu papel ativo neste processo por meio das tecnologias.

\subsection{Avaliação do curso}

Desde 2016, quando concluem o curso, os cidadãos respondem a uma pesquisa de reação para avaliação do mesmo. Apesar da dificuldade em obter-se feedback em tais avaliações, pós curso, percebe-se uma boa participação nesta importante fase do curso. Em 2016, 613 participantes responderam o questionário, em 2017 foram 601, em 2018 foram 1258. Em 2019, 894 e, por fim, em 2020, 857 cursistas participaram da avaliação.

Dos dados de 2018, reforça-se que, com relação ao questionamento: "O curso possibilitou melhorar a compreensão do tema?”, $84 \%$ assinalaram a opção 'ótimo', $15 \%$ assinalaram 'bom' e 1\% 'regular". Quando questionados sobre: "O curso contribuiu para minha formação profissional e o para o desempenho do meu trabalho?", $83 \%$ dos cidadãos assinalaram a opção ‘ótimo', 15\% optaram por 'bom' e 2\% como 'regular'.

$\mathrm{Na}$ questão "O curso contribuiu para o desempenho das suas atividades?", percebe-se a utilidade do curso para os participantes, conforme Tabela 5. Percebe-se que, ao longo dos anos, a avaliação foi sendo mais positiva, talvez porque foram sendo reforçados os aspectos relacionados a utilidade dos temas trabalhados no curso, bem como houve um reforço em demonstrar quais técnicas e ferramentas são utilizadas para o controle social.

Tabela 5. Contribuição do curso em atividades do cursista

\begin{tabular}{|c|c|c|c|c|c|}
\hline & $\mathbf{2 0 1 6}$ & $\mathbf{2 0 1 7}$ & $\mathbf{2 0 1 8}$ & $\mathbf{2 0 1 9}$ & $\mathbf{2 0 2 0}$ \\
\hline Ótimo & $69,30 \%$ & $75,8 \%$ & $83 \%$ & $78 \%$ & $88,08 \%$ \\
\hline Bom & $25,80 \%$ & $21,5 \%$ & $15 \%$ & $20 \%$ & $11,10 \%$ \\
\hline Regular & $4,70 \%$ & $2,6 \%$ & $2 \%$ & $2 \%$ & $0,70 \%$ \\
\hline Ruim & $0,20 \%$ & $0,1 \%$ & $0 \%$ & $0 \%$ & $0,12 \%$ \\
\hline
\end{tabular}

\footnotetext{
${ }^{1}$ Dados coletados em 19/07/21 às 15h20 de Brasília. 
Após a remodelagem do curso, realizada em 2015, na avaliação global, percebese um ligeiro aumento do conceito geral atribuído ao curso. Em 2019, o curso atingiu seu um alto índice, com $88 \%$ de conceito ótimo e nenhuma indicação para ruim, conforme demonstra a Tabela 6.

Tabela 6. Qual o seu conceito geral atribuído ao curso?

\begin{tabular}{|c|c|c|c|c|c|}
\hline Ano & $\mathbf{2 0 1 6}$ & $\mathbf{2 0 1 7}$ & $\mathbf{2 0 1 8}$ & $\mathbf{2 0 1 9}$ & $\mathbf{2 0 2 0}$ \\
\hline Ótimo & $77,30 \%$ & $81,2 \%$ & $84 \%$ & $88 \%$ & $94,63 \%$ \\
\hline Bom & $19,10 \%$ & $17,1 \%$ & $15 \%$ & $12 \%$ & $5,14 \%$ \\
\hline Regular & $3,60 \%$ & $1,5 \%$ & $1 \%$ & $0 \%$ & $0,23 \%$ \\
\hline Ruim & $0 \%$ & $0,2 \%$ & $0 \%$ & $0 \%$ & $0 \%$ \\
\hline \multicolumn{6}{|c}{ Fonte: Arquivos da Sai - TCE/MT. }
\end{tabular}

Contudo, em 2020, mesmo diante das adversidades advindas da pandemia e para surpresa da equipe gestora da ação, o curso atingiu seu maior índice, obtendo 94,63\% de aprovação sem nenhuma avaliação "ruim", como já havia acontecido em outros anos.

Com relação ao Ambiente Virtual de Aprendizagem utilizado para Educação a Distância, análises de aspectos pedagógicos e técnicos deste foram publicados e podem ser encontrados em Maciel et al. (2018) e em Andrade et al. (2019). De forma geral, é oportuno ressaltar que o aprimoramento das tecnologias de EaD contribuiu para o êxito do curso, tendo em vista a possibilidade de participar da proposta formativa por meio de plataforma on-line, bem como realizar as atividades remotamente. Tal contexto oportuniza um efetivo engajamento social, democratização do acesso ao conhecimento mediante práticas participativas dos sujeitos envolvidos no processo. Convém destacar que, no decurso dos anos, distintas tecnologias foram customizadas no AVA, com o propósito de prover estratégias para qualificar as ofertas de cursos $\mathrm{EaD}$, como os elementos de gamificação implementados no ambiente virtual, disponibilização de material textual em formato multimodal, ajustes de acessibilidade nos conteúdos e, ainda, o incremento de aulas síncronas, via webconferência.

\section{Considerações Finais}

Conforme discutido ao longo deste artigo, para a efetiva participação dos cidadãos na vida pública é necessário que estes estejam informados e motivados para exercer um papel ativo no exercício democrático. Um dos caminhos para estimularmos o engajamento e a participação social é a oferta de cursos de capacitação com a utilização das Tecnologias da Informação e da Comunicação. Neste caso, o uso de Educação a Distância foi fundamental para que o acesso ao conhecimento e às informações relacionadas à gestão pública chegassem, ao mesmo tempo e em diferentes lugares de um Estado de grande dimensão geográfica, atingindo ainda outros Estados.

Apesar das dificuldades enfrentadas pela democracia participativa e do baixo engajamento social, percebe-se que, nos últimos sete anos, têm crescido o número de cidadãos interessados em participar da formação em "Cidadania e Controle Social" ofertado pelo TCE-MT. Conforme demonstrado neste artigo, as estratégias utilizadas ao longo dos anos, pelo TCE-MT e UFMT, para oferta deste curso, permitiram a elevação no número de capacitados e melhoraram a efetividade do curso. Em suas sete edições, o 
curso capacitou até a fase final 4.947 alunos e contou com a presença de, pelo menos 60 diferentes profissionais e com expressiva média de aprovação. Dessa forma, apesar de haver um longo percurso a ser trilhado, reforça-se o interesse da sociedade em participar da capacitação com o tema "Cidadania e Controle Social", na modalidade EaD. As análises apontam para a importância do TCE-MT continuar oferecendo cursos de capacitação para o público de conselheiros municipais de políticas públicas e a sociedade em razão da elevada procura e a participação efetiva de públicos essenciais para a efetividade das políticas públicas.

Apesar de nascer para atender os conselhos de políticas públicas, os quais têm disponível metade das vagas em todas as edições do curso, a profissão na área administrativa foi a mais interessada no curso, após a abertura para a participação da sociedade. Em 2020, talvez pela pandemia, houve aumento dos profissionais da saúde interessados no curso. A aproximação e articulação entre o controle externo e a sociedade faz parte do espírito democrático constitucional e está inserida nas transformações que os tribunais e a própria sociedade vivenciaram nas últimas décadas. Ainda, percebe-se pelo nível de aprovação e pelos trabalhos finais que os cursistas, no decorrer desta aprendizagem, percebem a importância da participação e se empoderam no exercício do controle social na prática, deixando para trás a cultura reclamatória e vivenciando as oportunidades participativas.

O curso ofertado pelo Tribunal de Contas de Mato Grosso constitui-se em um conjunto de práticas educacionais planejadas para promover oportunidades de desenvolvimento ao cidadão, visando ajudá-lo a atuar de forma mais eficaz em sua vida na sociedade. Percebe-se que esta ação pode ser viabilizada por outros órgãos governamentais, mas seu exercício tem caráter subjetivo e deve surgir do interesse social. Cabe ressaltar que, na operacionalização do curso, a relação do órgão governamental em parceria com a universidade, agrega valor científico e tecnológico ao curso, com a expertise da academia com a EaD e a possibilidade de certificação dos concluintes.

Por outro lado, o TCE-MT tem utilizado o curso como promotor de uma maior participação social em seus processos e serviços, vez que, pela disponibilização de informações sobre sua atuação e pelas atividades requeridas nos módulos do curso, instiga os cursistas a acessarem seu portal, a utilizarem seus dados e refletirem, por exemplo, sobre as possibilidades da ouvidoria e sobre a Lei de Acesso a Informação. Em um ano atípico como o de 2020, o curso teve seu papel ainda mais reforçado e reconhecido, visto que as estratégias de comunicação via Internet foram potencializadas.

É importante apontar que tecnologias que promovem a participação dos cidadãos devem ser encaradas como meios, não fins. Elas não devem ser consideradas neutras, pois carregam valores, conceitos, visões sociais e processos conflitantes, privilegiados e excludentes, entre outros. Tecnologias foram criadas para resolver problemas concretos, portando estas possuem conteúdo político e social. Por si só, elas não garantem a participação ativa e crítica do cidadão em assuntos de interesses públicos. Assim, o sucesso desta estratégia não está diretamente relacionado aos meios empregados, ou seja, a tecnologia, mas à motivação dos cidadãos e governo em tornar este sucesso possível. Neste sentido, percebe-se que o conjunto de estratégias adotadas neste curso, ao longo dos anos, foi bem-sucedida e o compartilhamento dela pode estimular outros pares. E a contribuição do artigo corresponde justamente em ofertar o relato desta experiência, 
embasado por referenciais da área, com registro das mudanças realizadas ao longo dos anos.

Todavia, reflexões devem ser endereçadas no sentido de incorporar outras técnicas e tecnologias que permitam novas discussões e formações no curso, visando capacitar o cidadão a colaborar diretamente com o governo, através, por exemplo, do acesso a Dados Abertos Governamentais (Beluzo et al., 2021) e recuperação da informação (Barcellos; Bernardini e Viterbo, 2020), podendo fazer uso da estratégia da gamificação (Zann et al., 2021), bem como utilizando aplicações de governo eletrônico que se baseiam em dados coletados de um grande número de cidadãos (Citizen-Sourcing applications) (Monteiro et al., 2021). Como limitações do estudo, sob o ponto de vista do percurso metodológico escolhido, cita-se a não manipulação de variáveis de forma correlacionada e de técnicas estatísticas mais robustas. Considerando este ser um levantamento, é limitada também a profundidade do estudo quanto a estrutura e processos envolvidos com a oferta do curso e do seu impacto para a sociedade sob o ponto de vista qualitativo. Ainda, os dados apresentados neste artigo corroboram com outros publicados sobre partes específicas do curso e citados ao longo dele. Salienta-se que, conhecer o perfil do público e sua opinião é fundamental para a oferta de estratégias educativas para o exercício democrático.

Alguns pontos da experiência merecem atenção e pesquisa por parte do TCEMT e da própria academia, como questões relacionadas a interação no ambiente virtual e as evidências encontradas de que o curso tem auxiliado no controle social por parte dos que participam do curso. Também, os dados podem ser analisados sob outras óticas, como por exemplo, do gênero e classes sociais dos participantes. Cabe reforçar que esta experiência está centrada em um país, com seus marcos legais e cultura, todavia pode ser replicado em outros contextos.

Acredita-se que, a partir desta experiência, abre-se o caminho para uma nova concepção de capacitação e estímulo ao engajamento social, no qual o cidadão, seja ele um conselheiro ou não, é protagonista e o principal agente social no exercício da reflexão e discussão das problemáticas que afetam a vida democrática coletiva.

\section{Referências}

Akutsu, L. and Pinho, J. A. G. (2002) "Sociedade da informação, accountability e democracia delegativa: investigação em portais do governo" In: Revista de Administração Pública. Rio de Janeiro, FGV, v. 36, n. 5, p. 723-45.

Andrade, M. B. S. M. de; dos Anjos, R. A. V. and dos Anjos, A. M. (2019) "Cursos à Distância do Tribunal de Contas de Mato Grosso: dimensões técnica, pedagógica e instrucional" In: Coutinho, D. de M.; Gonçalves, A. L. De M. (Org.). Contando saberes: algumas experiências das escolas de contas e gestão. Palmas : Instituto de Contas. https://irbcontas.org.br/wp-content/uploads/2020/04/Contando-Saberes.pdf.

Astrom, J. Should democracy online be quick, strong, or thin? Communications of the ACM. Ano 44, v.1, p. 49-51, jan. 2001.

Barber, B. Strong democracy: participatory politics for a new age. Twentiethanniversary Ed. Berkeley. Londres: University of California Press, 2004. 356 p.

Barcellos, R,; Bernardini, F,; Viterbo, J,. A Methodology for Retrieving Datasets from Open Government Data Portals Using Information Retrieval and Question and 
Answering Techniques. In: International Conference on Electronic Government. Springer, Cham, 2020. p. 239-249.

Beluzo, J. R. et al. Re-Public: workflow to publish and reuse Linked Open Government Data. In: XVII Brazilian Symposium on Information Systems. 2021. p. 1-7.

Benevides, M. V. de M. A. (1996) "Cidadania ativa: referendo, plebiscito e iniciativa popular” 2. ed. São Paulo: Ática.

Brasil. (1988) “Constituição - Emenda Constitucional n. ' 19, de 04 de junho de 1998”. Modifica o regime e dispõe sobre princípios e normas da Administração Pública, servidores e agentes políticos, controle de despesas e finanças públicas e custeio de atividades a cargo do Distrito Federal, e dá outras providências. http://www.planalto.gov.br/ccivil 03/Constituicao/Emendas/Emc/emc19.htm

Brasil. (1988) “Constituição da República Federativa do Brasil”. Brasília, DF: Senado, 1988. http://www.planalto.gov.br/ccivil_03/Constituicao/Constituicao.htm.

Brasil. (2000) "Lei Complementar n. . 101, de 04 de maio de 2000”. Estabelece normas de finanças públicas voltadas para a responsabilidade na gestão fiscal e dá outras providências. http://www.planalto.gov.br/ccivil 03/leis/LCP/Lcp101.htm.

Brasil. (2009) "Lei Complementar n. ${ }^{\circ}$ 131, de 27 de maio de 2009”. Estabelece normas de finanças públicas voltadas para a responsabilidade na gestão fiscal e dá outras providências, a fim de determinar a disponibilização, em tempo real, de informações pormenorizadas sobre a execução orçamentária e financeira da União, dos Estados, do Distrito Federal e dos http://www.planalto.gov.br/ccivil_03/leis/LCP/Lcp131.htm.

Brasil. (2011) "Lei ${ }^{\circ}$ 12.527, de 18 de novembro de 2011". Regula o acesso a informações previsto no inciso XXXIII do art. $5^{\circ}$, no inciso II do $\S 3^{\circ}$ do art. 37 e no $\S 2^{\circ}$ do art. 216 da Constituição Federal; altera a Lei $n^{\circ} 8.112$, de 11 de dezembro de 1990; revoga a Lei $n^{\circ} 11.111$, de 5 de maio de 2005, e dispositivos da Lei $n^{\circ} 8.159$, de 8 de janeiro de 1991; e dá outras providências. http://www.planalto.gov.br/ccivil 03/ ato2011-2014/2011/lei/112527.htm.

Bresser Pereira, L. C. (1997) "Cidadania e res publica: a emergência dos direitos republicanos” In: Revista de Informação Legislativa. Brasília: 34, n. 136, p. 289-313.

Brito, A. (2001) "O Regime Constitucional dos Tribunais de Contas" In:Revista Diálogo Jurídico, Salvador, v. 1, nº 9.

Campos, A. M. (1990) "Accountability: quando poderemos traduzi-la para o português?” In: Revista de Administração Pública, Rio de Janeiro, FGV, v. 24, n. 2, p. 30-50.

de Souza, G.P. and Maciel, C. (2008) "The Voting Processes in Digital Participative Budget: A Case Study" https://dl.gi.de/handle/20.500.12116/29186; In: Krimmer,R.; Grimm, R.. (Org.). Electronic Voting. Bonn: Köllen Druck Verlag, v. P-131, p. 249259.

Eirado, M.G.G. Percepções sobre a educação a distância: um estudo preliminar à implantação da EaD pela Escola de Contas Públicas do TCDF. 2017. 51 f. Trabalho 
de Conclusão de Curso (Especialização em Gestão Pública), Universidade de Brasília, Brasília, 2017.

Ellery, A.P.C.; Vidal, E.M. Ambientes de aprendizagem utilizando mídias sociais na web como ferramenta de controle social e de apoio à gestão pública: um caminho para o e-government 2.0. In: XIII Congreso de Educación a Distancia CREAD UDEC 2009. https://reposital.cuaieed.unam.mx:8443/xmlui/handle/20.500.12579/2880

Felix, G. da S.; de Figueirêdo, B.C.B. a educação corporativa como ferramenta de controle social: a implantação do sicap no TCE/RR. IN: IV Congresso Nacional de Educação, 2017. https://www.editorarealize.com.br/editora/anais/conedu/2017/TRABALHO_EV073_ MD1_SA5_ID4186_09092017192913.pdf

Girata, N. N. H. and Maciel, C. eGov website evolution study within strategic planning. In: Proceedings of the 15th Annual International Conference on Digital Government Research. 2014. p. 69-78. https://doi.org/10.1145/2612733.2612774

Gondim, S. M. G. (2003) "Grupos focais como técnica de investigação qualitativa: desafios metodológicos" In: Paidéia: Cadernos de Psicologia e Educação, v. 12, n. 24, p. 149-161.

Instituto Rui Barbosa. (2020) A casa do conhecimento dos Tribunais de Contas. https://irbcontas.org.br/

Islam, M. S. Towards a sustainable e-Participation implementation model. European Journal of ePractice, v. 5, n. October, p. 1-12, 2008.

Lima, L. H. (2015) "Controle Externo - Teoria e Jurisprudência para os Tribunais de Contas" 6. ed. São Paulo: Método.

Maciel, C., Cappelli, C., Slaviero, C. and Garcia, A. C. B.. Technologies for popular participation: a research agenda. In: Proceedings of the 17th International Digital Government Research Conference on Digital Government Research. 2016. p. 202211. DOI: https://dl.acm.org/doi/10.1145/2912160.2912191

Maciel, C.; Roque, L.; and Garcia, A. C. B.. Democratic citizenship community: a social network to promote e-deliberative process. In: Proceedings of the 10th Annual International Conference on Digital Government Research: Social Networks: Making Connections between Citizens, Data and Government. 2009. p. 25-34. DOI: https://dl.acm.org/doi/10.5555/1556176.1556187

Maciel, C.; Vuolo, C.; Sambrano, T. M.; Anjos, A. M.; Kuhn, A. P. and Rouiller, C. O. (2018) "Connecting, Integrating and Empowering Society for Social Control Through Distance Education" In: Lecture Notes in Computer Science, v. 11032, p. 108-122. DOI: https://doi.org/10.1007/978-3-319-98349-3 9

Maciel, C.; Garcia, A. C. B.; and Pinto, F.B. e Democracia. In: Cristiano Maciel; José Viterbo. (Org.). COMPUTAÇÃO E SOCIEDADE: A SOCIEDADE - VOLUME 2. https://bit.ly/38UTTIp. 1ed.Cuiabá: EdUFMT - Editora da Universidade Federal de Mato Grosso, 2020, v. , p. 108-140.

Mendonça Filho, M. C. (2000) "A noção de segurança democrática como alternativa para a crise da função policial”. (mimeo.), p. 13. 
Monteiro, M. et al. Assessing the Quality of Local E-Government Service Through Citizen-Sourcing Applications. In: 2021 IEEE 24th International Conference on Computer Supported Cooperative Work in Design (CSCWD). IEEE, 2021. p. 11781183.

Moreira, N. and Figueiredo, D. (2004) "Parlamento e a Sociedade como destinatários do trabalho dos Tribunais de Contas" In: Revista do TCE-SC, p. 113-114.

Oliveria, D. (2017) "Taxa de evasão em cursos on-line chega a 50\% e desafia instituições" Folha de São Paulo. São Paulo-SP: Folhapress. https://www1.folha.uol.com.br/educacao/2017/07/1904627-taxa-de-evasao-emcursos-on-line-chega-a-50-e-desafia-instituicoes.shtml

Roberts, N. (2004) "Public Deliberation in an Age of Direct Citizen Participation" In: The American Review of Public Administration, (34) 4, p. 315-353.

TCE Mato Grosso. (2020) "Aula Inaugural do Curso de Extensão: Cidadania e Controle Social”. https://www.youtube.com/watch?v=DPRgGazLJGM

TCE Mato Grosso. (2020) "Live TCE-MT - Transparência e controle social". https://www.youtube.com/watch?v=DaMnPVbcKwE

TCE Mato Grosso. RESOLUÇÃO NORMATIVA No 12/2013. Dispõe sobre a Instituição Definitiva do Programa de Desenvolvimento Institucional Integrado, no âmbito do Tribunal de Contas do Estado de Mato Grosso. 2013. Disponível em: https://jurisdicionado.tce.mt.gov.br/arquivos/downloads/00037908/Resolu\%C3\%A7 \%C3\%A3o\%20Normativa $\% 20$ n\%C2\%BA\%2012\%20_2013.pdf

Vuolo, C. (2008) "Os Tribunais de Contas como instrumento de construção da cidadania" In: Tribunal de Contas: defesa do interesse público e combate à corrupção; Anais do XXIV Congresso Nacional dos Membros dos Tribunais de Contas do Brasil: comemoração dos 50 anos do Tribunal de Contas do Rio Grande do Norte. Belo Horizonte: Fórum.

Vuolo, C. (2016) "Os Tribunais de Contas do Brasil na Democratização da Gestão Pública, à luz da Constituição Federal de 1988" Universidad Del Museo Social Argentino. Departamento de Posgrado. Doctorado en Ciencias Juridicas y Sociales. p. 276. Tese de Doutorado.

Vuolo, C. L. C.; Maciel, C.; Auerswald, A. A. G. B.; Dos Anjos, R. A.; Dos Anjos, A. M.; De Oliveira, C. S. and Mansilla, D.P. Formando Cidadãos para a Cidadania e Controle Social: Levantamentos de uma Experiência. In: WORKSHOP DE COMPUTAÇÃO APLICADA EM GOVERNO ELETRÔNICO (WCGE), 8. , 2020, Cuiabá. Anais [...]. Porto Alegre: Sociedade Brasileira de Computação, 2020 . p. 1223. DOI: https://doi.org/10.5753/wcge.2020.11254.

Vuolo, C.; Maciel, C. and Anjos, A. (2018) "Educação a Distância: [In]Formação em Cidadania e Controle Social" Cuiabá-MT: EdUfmt, http://www.editora.ufmt.br/download/livro3 ead_ePUB2018.pdf.

Vuolo, C.; Silva, R. C. R. and Souza, B. J. R. (2017) "Os Conselhos Municipais de Políticas Públicas em Mato Grosso: mapeamento, desempenho e perspectivas" Cuiabá-MT: PubliContas, 128 p. 
Zahn, J.; Da Silva, M.; Mourão, E.; Gracioli Neto, C.; Grilo, E. S.; Viterbo, J.; Bernardini, F. C. Ajuda aí, Sinop!: Uma ferramenta para crowdsourcing com gamificação aplicada a cidades inteligentes. In: WORKSHOP DE COMPUTAÇÃO APLICADA EM GOVERNO ELETRÔNICO (WCGE), 9. 2021, Evento Online. Anais [...]. Porto Alegre: Sociedade Brasileira de Computação, 2021. p. 191202. DOI: https://doi.org/10.5753/wcge.2021.15988. 